\title{
Inhibitory activity of monoacylglycerols on biofilm formation in Aeromonas hydrophila, Streptococcus mutans, Xanthomonas oryzae, and Yersinia enterocolitica
}

\author{
Youngseok Ham and Tae-Jong Kim ${ }^{*}$ (D)
}

\begin{abstract}
Biofilm provides a bacterial hiding place by forming a physical barrier and causing physiological changes in cells. The elimination of biofilm is the main goal of hygiene. Chemicals that are inhibitory to biofilm formation have been developed for use in food, personal hygiene products, and medical instruments. Monoacylglycerols are recognized as safe and are used in food as emulsifiers. In this study, the inhibitory activity of monoacylglycerols on bacterial biofilm formation was evaluated systematically with four bacterial strains, Aeromonas hydrophila, Streptococcus mutans, Xanthomonas oryzae, and Yersinia enterocolitica. Monoacylglycerols with two specific lengths of fatty acid moiety, monolaurin and monobehenin, were found to have strong inhibitory activity toward bacterial biofilm formation of S. mutans, X. oryzae, and Y. enterocolitica in a strain specific manner. First, this result suggested that biofilm formation was not inhibited by the detergent characteristics of monoacylglycerols. This suggestion was supported by the inhibitory action of monolaurin on biofilm development but not on the initial cell attachment of Y. enterocolitica in flow cytometric observation. Second, it was also suggested that two distinct response mechanisms to monoacylglycerols existed in bacteria. The existence of these two inhibitory response mechanisms was bacterial strain specific.
\end{abstract}

Keywords: Aeromonas hydrophila, Streptococcus mutans, Xanthomonas oryzae, Yersinia enterocolitica, Biofilm formation, Monoacylglycerol

\section{Background}

Bacterial biofilm is the primary source of bacterial persisting contamination. Without biofilm formation, bacteria can be easily washed away. Even before producing a mature biofilm, the condition for bacterial biofilm formation induces bacterial cells to stick together on a hard surface which is the initiation of biofilm formation and makes it difficult to remove bacteria during the process of biofilm formation. However, the function of biofilm as a contamination source is not only due to the difficulty of removing bacteria physically but also due to the physiological changes in cells that increase their resistance

\footnotetext{
*Correspondence: bigbell@kookmin.ac.kr

Department of Forest Products and Biotechnology, College of Forest

Science, Kookmin University, 77 Jeongneung-ro, Seongbuk-gu,

Seoul 02707, Korea
}

to physical, chemical, and biological stresses (Park et al. 2015; Parsek and Singh 2003).

Monoacylglycerols are organic compounds which are consisted with glycerol linked to one fatty acid via an ester bond. They exist in some seeds naturally and can be synthesized in cells as intermediate compounds in the process of synthesis and hydrolysis of triacylglycerols. Monoacylglycerols are generally recognized as safe by the US Food and Drug Administration, and are used as emulsifiers in commercial food products. Some monoacylglycerols inhibit bacterial growth and also change bacterial physiology as follows. Monocaprylin is toxic to Cronobacter sakazakii and Cronobacter malonaticus (Marounek et al. 2012). Monocaprin has shown antimicrobial activities against Streptococcus mutans (Ósk Thorgeirsdóttir et al. 2006). Monolaurin inhibited 
growth and reduced exotoxin production in Staphylococcus aureus (Schlievert et al. 1992) and also inhibited the expression of virulence factors in S. aureus (Ruzin and Novick 2000). In addition, it inhibited the production of virulence factors in Bacillus anthracis (Vetter and Schlievert 2005), and repressed the induction of vancomycin resistance in Enterococcus faecalis (Ruzin and Novick 1998). Monoacylglycerols inhibited the growth of food-borne pathogens or spoilage bacteria strains, and monolaurin especially showed strong inhibition of the cell growth of five strains: Bacillus cereus, B. subtilis, E. faecalis, Micrococcus luteus, and S. aureus (Buňková et al. 2011). Monocaprin, monolaurin, and monomyristin inhibited the growth of several Gram-positive strains and monolaurin had the most effective inhibitory activity (Batovska et al. 2009). In addition, monolaurin (Chavant et al. 2004; Oh and Marshall 1996) and its formulations (Hess et al. 2014; Lester and Simmonds 2012; Rouse et al. 2005) showed a bactericidal activity on cells in biofilm.

In addition to their bactericidal activity, the inhibition of biofilm formation by monoacylglycerols can be expected because of their surfactant properties (Thanomsub et al. 2004). However, the inhibitory efficacy of monoacylglycerols on biofilm formation has not been well evaluated. Monolaurin inhibited biofilm formation in S. aureus and Haemophilus influenzae in addition to their bactericidal activity (Schlievert and Peterson 2012). In this study, the inhibitory activity of monoacylglycerols against biofilm formation in four bacterial strains, Aeromonas hydrophila, S. mutans, Yersinia enterocolitica, and Xanthomonas oryzae, was evaluated. A. hydrophila is a major pathogen of fish and amphibians (Khalil et al. 2013; McGarey et al. 1991). S. mutans exists in the human oral cavity (Struzycka 2014) and is a major contributor to the development of dental caries (Forssten et al. 2010). $Y$. enterocolitica is an opportunistic pathogen that causes yersiniosis (Koornhof et al. 1999; Smego et al. 1999), which is a serious problem in infected children under the age of one (Abdel-Haq et al. 2000). X. oryzae is a plant pathogen that causes bacterial blight in rice (Shen and Ronald 2002). Among these four bacterial strains, the inhibitory effect of monolaurin on biofilm formation in $S$. mutans was investigated, particularly as an oral hygiene compound.

\section{Methods}

\section{Bacterial strains and culture media}

Aeromonas hydrophila and S. mutans were obtained from the Research Institute of LG Household a Health Care Co., Ltd. (Daejeon, Korea). X. oryzae (KACC 10331) and $Y$. enterocolitica (KCCM 41657) were obtained from the Genebank Information Center in the Rural Development Administration (Jeonju, Korea) and Korean Culture Center of Microorganisms (Seoul, Korea), respectively.

YGC agar plates were made with $50 \mathrm{~g} / \mathrm{l}$ of glucose, $5 \mathrm{~g} / \mathrm{l}$ of yeast extract, $12.5 \mathrm{~g} / \mathrm{l}$ of $\mathrm{CaCO}_{3}$, and $15 \mathrm{~g} / \mathrm{l}$ of agar. M210 medium and XOM2 medium were prepared as previously described by Zhang et al. (2013) and Tsuge et al. (2002), respectively. LB agar plates were made with $25 \mathrm{~g} / \mathrm{l}$ of LB broth (Becton, Dickinson, and Company, Franklin Lakes, NJ, USA) and 15 g/l of agar. TYE medium was made with $10 \mathrm{~g} / \mathrm{l}$ of tryptone and $5 \mathrm{~g} / \mathrm{l}$ of yeast extract. M63G medium (100 ml) was made with $20 \mathrm{ml}$ of $5 \times$ minimal M63 medium $\left(15 \mathrm{~g} / \mathrm{l}\right.$ of $\mathrm{KH}_{2} \mathrm{PO}_{4}$, $35 \mathrm{~g} / \mathrm{l}$ of $\mathrm{K}_{2} \mathrm{HPO}_{4}, 10 \mathrm{~g} / \mathrm{l}$ of $\left(\mathrm{NH}_{4}\right)_{2} \mathrm{SO}_{4}$, and $2.5 \mathrm{mg} / \mathrm{l}$ of $\mathrm{FeSO}_{4}$ ), $1 \mathrm{ml}$ of $20 \%$ glucose, $0.1 \mathrm{ml}$ of $20 \% \mathrm{MgSO}_{4}$, and filled with water. BHI medium was made with $37 \mathrm{~g} / \mathrm{l}$ of brain heart infusion broth (Becton, Dickinson, and Company). To make BHI agar plates, $15 \mathrm{~g} / \mathrm{l}$ of agar was additionally added to BHI medium. To make BHI-S medium, $10 \mathrm{~g} / \mathrm{l}$ of sucrose was additionally added to BHI medium (Beckloff et al. 2007; Coenye et al. 2007). Tryptone soy broth with yeast extract (TSBY) was prepared as previously described (Kirov et al. 2004).

\section{Monoacylglycerols}

Monocaprylin (1-octanoyl-rac-glycerol, catalog number: M2265) and monocaprin (1-decanoyl-rac-glycerol, catalog number: M2140) were purchased from SigmaAldrich Korea Co. (Seoul, Korea). Monolaurin (1-lauroylrac-glycerol, catalog number: G0081) was purchased from Tokyo Chemical Industry Co., LTD (Tokyo, Japan). Monomyristin (1-myristoyl-rac-glycerol, catalog number: $\mathrm{O}-1335)$ and monopalmitin (1-palmitoyl-rac-glycerol, catalog number: O-1420) were purchased from Bachem AG (Bubendorf, Switzerland). Monostearin (1-stearoylrac-glycerol, catalog number: 43883) was purchased from Alfa Aesar (Seoul, Korea). Monoarachidin (1-arachidoylrac-glycerol, catalog number: 31-2000) and monobehenin (1-behenoyl-rac-glycerol, catalog number: 31-2200) were purchased from Indofine Chemical Company, Inc. (Hillsborough, NJ, USA).

\section{Biofilm formation in 96-well microplates}

Xanthomonas oryzae stored at $-80{ }^{\circ} \mathrm{C}$ was streaked on YGC agar plates and incubated at $28^{\circ} \mathrm{C}$ for 2 days. A single colony was inoculated in $5 \mathrm{ml}$ of M210 and incubated at $28{ }^{\circ} \mathrm{C}$ and $250 \mathrm{rpm}$ for 2 days. The cell density of the culture was measured at $\mathrm{A}_{600}$. The cultured cells were inoculated in $100 \mu \mathrm{l}$ of XOM2 media in 96-well polyvinyl chloride (PVC) microplates with 0.05 of $\mathrm{A}_{600}$ as the final cell concentration. The cells in the microplates were 
incubated at $28^{\circ} \mathrm{C}$ for $24 \mathrm{~h}$ and the amount of biofilm was quantified using crystal violet.

Yersinia enterocolitica biofilm was produced according to a previously described method (Kim et al. 2008).

Streptococcus mutans biofilm was produced according to a method previously described for $X$. oryzae with some modifications for $S$. mutans. All cultures were cultivated at $37^{\circ} \mathrm{C}$. BHI agar plates were used to obtain a single colony from the stored strain and BHI medium was used to prepare a pre-culture for 1 day. BHI-S medium was used for biofilm formation in 96-well PVC microplates.

Aeromonas hydrophila biofilm was also produced according to a method previously described for $X$. oryzae with some modifications for $A$. hydrophila. All cultures were cultivated at $30^{\circ} \mathrm{C}$. LB agar plates were used to obtain a single colony from the stored strain for 1 day and LB medium was used to prepare a pre-culture for 1 day. TSBY medium was used for biofilm formation in 96-well PVC microplates.

\section{Cell density and bacterial biofilm quantification using crystal violet}

After $24 \mathrm{~h}$ of biofilm formation in 96-well PVC microplates, optical density of each well at $595 \mathrm{~nm}$ was measured before quantitative analysis of biofilm using an Opsys MR microplate reader (Dynex Technologies, Chantilly, VA, USA). The cell density was correlated with the optical density at $595 \mathrm{~nm}$. Quantitative analyses of biofilms were performed using the crystal violet assay as described in a previous study (Kim et al. 2008) with a change of all incubation times from 20 to $15 \mathrm{~min}$. The optical density at $595 \mathrm{~nm}$ of each well was also measured using an Opsys MR microplate reader.

\section{Biofilm formation in continuous-culture flow cells}

Biofilm formation of $S$. mutans in a flow cell system was observed as reported in a previous experiment with some modifications (Kim et al. 2008). The flow cells and the bubble traps were purchased from the Center for Biomedical Microbiology (Technical University of Denmark, Lyngby, Denmark). The flow cells were covered with microscope coverslips made from polyvinyl chloride. Media were fed using a peristaltic pump (Masterflex L/S Digital Drive EW-07523-90, Masterflex L/S 12-channel, 8-roller cartridge pump head EW-07519-25, Masterflex L/S small cartridges EW-07519-85, Cole-Parmer Instrument Company, LLC., Vernon Hills, IL USA).

First, monolaurin was dissolved in methanol and mixed with media in order to facilitate dissolution. The final concentration of monolaurin in BHI-S medium was 95 or $190 \mathrm{mg} / \mathrm{l}$ with $0.48 \%$ methanol. S. mutans was incubated in $5 \mathrm{ml}$ of $\mathrm{BHI}$ medium for $24 \mathrm{~h}$ at $37^{\circ} \mathrm{C}$ without shaking. The cells were diluted to an $\mathrm{OD}_{600}$ of 0.15 with BHI-S media and inoculated in a $350 \mu \mathrm{l}$ volume. The flow cells were incubated for $1 \mathrm{~h}$ with the coverslip side down. The flow cells were turned over and fed with media for $24 \mathrm{~h}$ at a speed of $13 \mathrm{ml} / \mathrm{h}$ according to a previous study (Wen et al. 2006). Biofilm formed on the coverslips was observed after 1 and $24 \mathrm{~h}$ of incubation using an Axio Scope.A1 microscope (Carl Zeiss Co., LTD., Seoul, Korea) with ZEN microscope software (Carl Zeiss Co., LTD.).

\section{Measuring the sterilization effect of monolaurin on $S$. mutans in a planktonic growth}

The inhibitory activity of monolaurin on the growth of $S$. mutans was measured by the colony forming unit (CFU) method. The monolaurin was dissolved in $10 \%$ methanol immediately before treatment. Monolaurin was tested with various concentrations ranging up to $190 \mathrm{mg} / \mathrm{l}$. The cells were incubated in BHI broth at $37^{\circ} \mathrm{C}$ for $24 \mathrm{~h}$ as a pre-culture. The cultured cells with 0.05 of $\mathrm{A}_{600}$ as a final cell concentration were inoculated into $2 \mathrm{ml} \mathrm{BHI} \mathrm{media}$ with $1 \%$ sucrose and the test concentration of monolaurin. Cells were additionally incubated at $37{ }^{\circ} \mathrm{C}$ for $24 \mathrm{~h}$. The homogeneous culture solution $(100 \mu \mathrm{l})$ was spread onto BHI agar plates after serial dilution. The spread plates were incubated at $37{ }^{\circ} \mathrm{C}$ for $48 \mathrm{~h}$ and the number of colonies was counted. All experiments were repeated three times at each concentration.

\section{Results and discussion}

The effect of monoacylglycerols on biofilm formation was evaluated according to the carbon skeleton length of the fatty acid moiety using four bacterial strains, $A$. hydrophila, S. mutans, X. oryzae, and Y. enterocolitica. In the case of A. hydrophila, all tested monoacylglycerols did not change biofilm formation in the tested concentration range (Fig. 1a; Additional file 1: Fig. 1A). There was no effect of the tested monoacylglycerols on biofilm formation of A. hydrophila.

Monoacylglycerols clearly altered biofilm formation in S. mutans in a carbon skeleton length-specific manner (Fig. 1b; Additional file 1: Fig. 1B). Monocaprylin did not have any distinct inhibitory activity on biofilm formation. Monocaprin began to have inhibitory activity by $7 \%$ with $48 \mathrm{mg} / \mathrm{l}$ (Additional file 1: Fig. 1B). Monolaurin had the strongest inhibitory activity, reducing biofilm formation by $66 \%$ with $48 \mathrm{mg} / \mathrm{l}$ of monolaurin having a similar inhibitory effect on biofilm formation in S. aureus (Schlievert and Peterson 2012). Monomyristin began to relieve the inhibitory activity on biofilm formation and had similar inhibitory activity to that of monocaprin, 

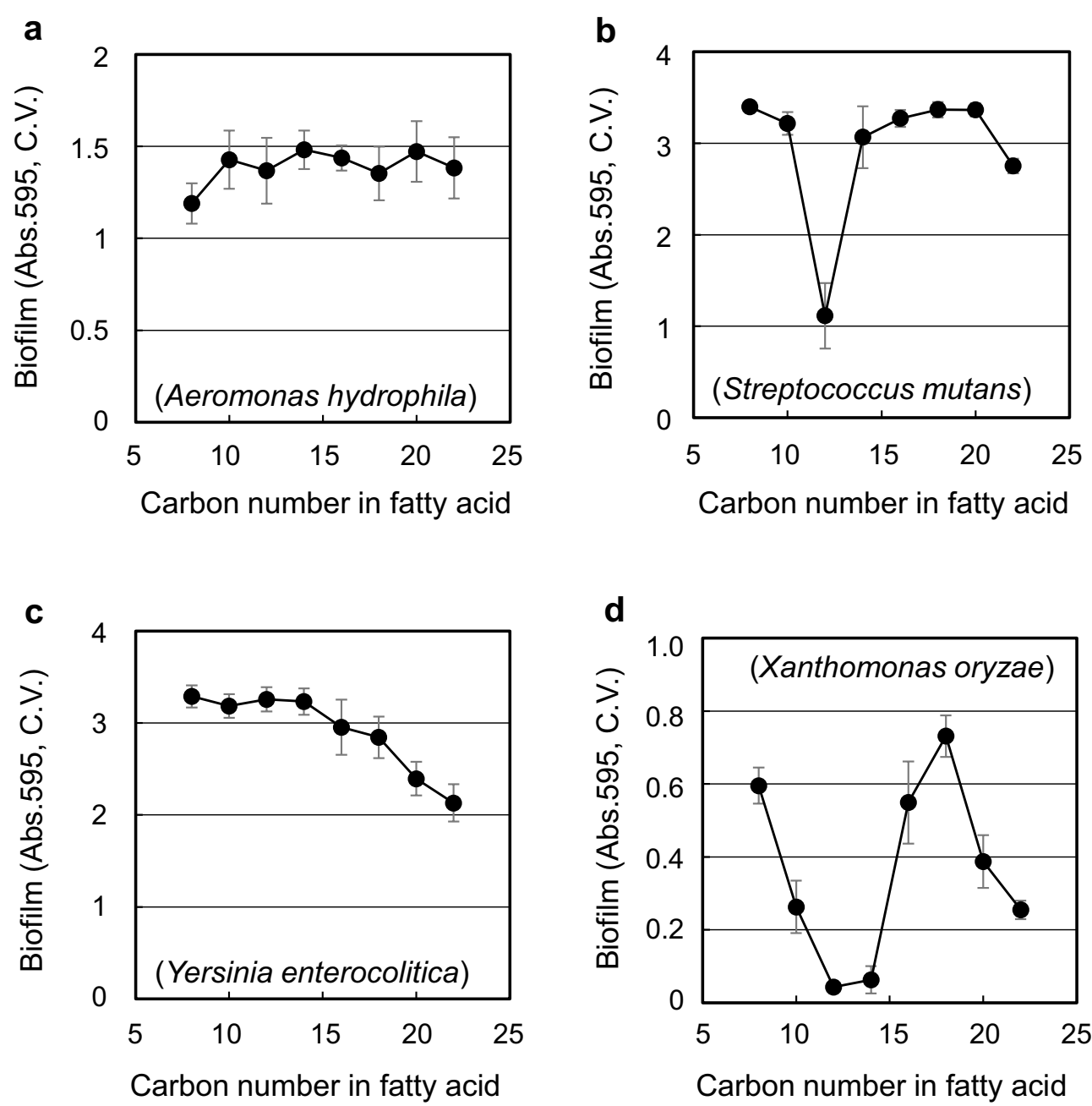

Fig. 1 Effect of the fatty acid length of monoacylglycerols on biofilm formation by four bacterial strains, a A. hydrophila, b S. mutans, $\mathbf{c} Y$. enterocolitica, and $\mathbf{d} X$. oryzae. The concentration effect of each monoacylglycerol was first observed in Additional file 1: Fig. 1. Because the results obtained with $48 \mathrm{mg} / \mathrm{l}$ clearly demonstrated the effectiveness of monoacylglycerols on biofilm formation, we selected $48 \mathrm{mg} / \mathrm{l}$ treatment data and replotted only selected data here. The biofilm amount was evaluated with $1 \%$ crystal violet. Data points are the average of eight experiments and are presented as mean \pm SD

$10 \%$ inhibition with $48 \mathrm{mg} / \mathrm{l}$. Monopalmitin, monostearin, and monoarachidin did not have any inhibitory activity, while the inhibitory activity of monobehenin was minor. To summarize the results, monolaurin had the strongest inhibitory activity on biofilm formation in $S$. mutans.

Biofilm formation of $Y$. enterocolitica was not inhibited by monocaprylin, monocaprin, monolaurin, or monomyristin but started to be inhibited by monopalmitin and longer monoacylglycerols (Fig. 1c; Additional file 1: Fig. 1C). The longer the carbon skeleton monoacylglycerols had, the stronger the inhibitory activity they had among monopalmitin and longer monoacylglycerols.
Monoacylglycerols inhibited the biofilm formation of $X$. oryzae, much like $S$. mutans but with stronger effects (Fig. 1d; Additional file 1: Fig. 1D). The strong inhibitory activity on biofilm formation was observed in two different ranges of carbon skeleton length. One range was with monolaurin and monomyristin and the other was with monobehenin.

Because $S$. mutans is a major bacteria in dental plaque and its acid production causes tooth decay, the inhibitory activity of monoacylglycerols on biofilm formation in $S$. mutans was investigated more thoroughly than that of other strains in this study. The inhibitory activity of monolaurin on biofilm formation of $S$. mutans showed that 
biofilm formation was inhibited and the inhibitory effect was correlated with the monolaurin concentration above $24 \mathrm{mg} / \mathrm{l}$ (Fig. 2a). The cell growth during biofilm formation was inhibited in the same way (Fig. 2b). However, the inhibitory activity of monolaurin was different between cells in planktonic growth and cells in biofilm (Fig. 2b, c).
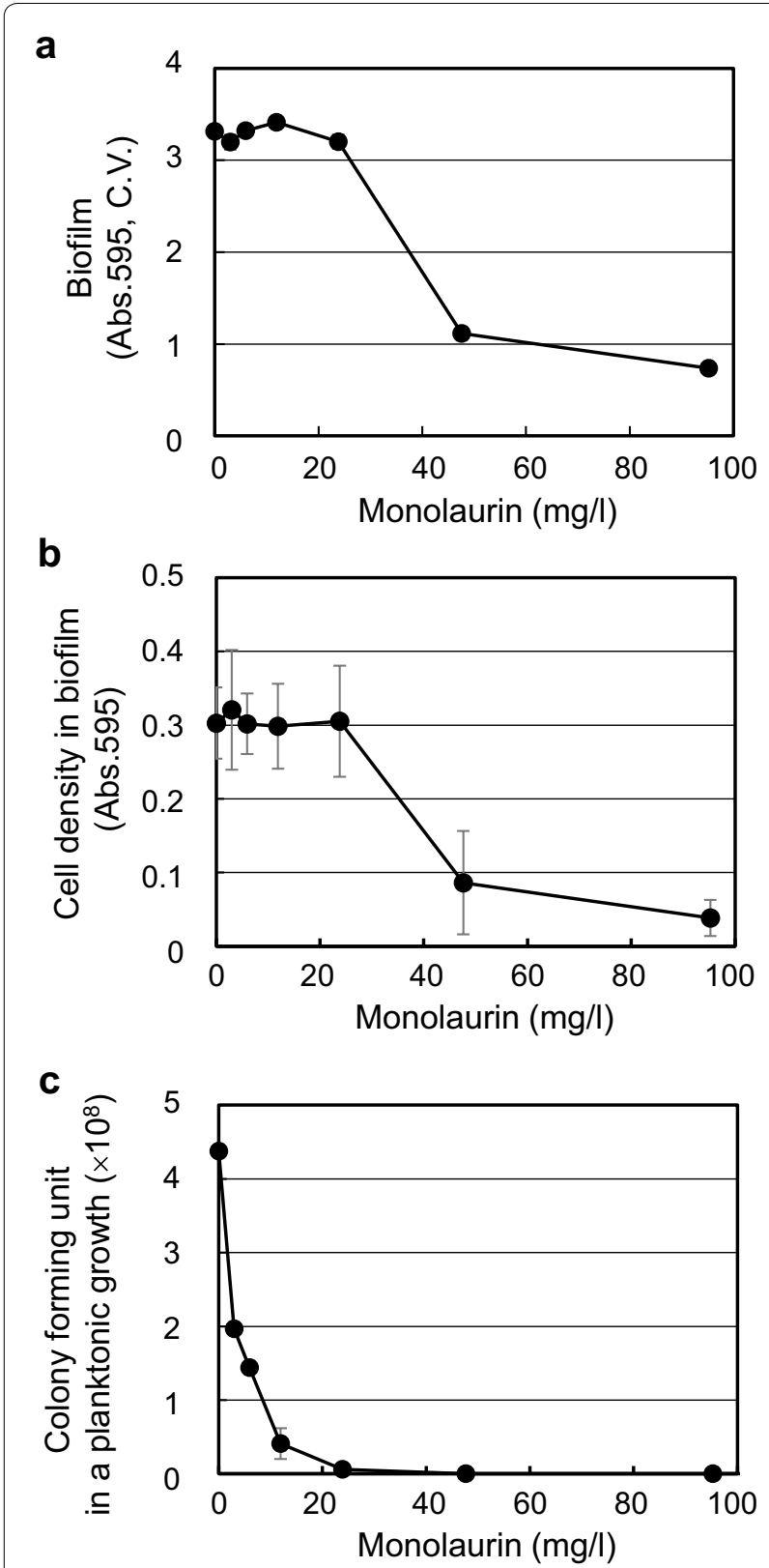

Fig. 2 The inhibitory effects of monolaurin on S. mutans. The effects of monolaurin on a biofilm formation, $\mathbf{b}$ cell growth in biofilm, and $\mathbf{c}$ cell growth in a planktonic growth of $S$. mutans were evaluated
Monolaurin at $3 \mathrm{mg} / \mathrm{l}$ strongly inhibited planktonic cell growth but the cell growth in biofilm was not inhibited up to $24 \mathrm{mg} / \mathrm{l}$ monolaurin. This result clearly demonstrated the increased resistance of $S$. mutans in biofilm to the monolaurin treatment. In the case of $Y$. enterocolitica and $X$. oryzae, there was no strong correlation between biofilm formation and cell growth when cells were treated with monoacylglycerols (Additional file 1: Fig. 2C, D). Therefore, monoacylglycerols might inhibit biofilm formation in both $Y$. enterocolitica and $X$. oryzae by different biological mechanisms than it does in S. mutans.

Based on the results in Fig. 1, not all monoacylglycerols had inhibitory activity on biofilm formation. There were two types of inhibitory monoacylglycerols in the carbon skeleton length of the fatty acid moiety. One type of fatty acid moiety in monoacylglycerols was similar in carbon skeleton length to that of monolaurin, which consists of glycerol and lauric acid $\left(\mathrm{C}_{12}\right)$, and the other was similar in carbon skeleton length to that of monobehenin, which consists of glycerol and behenic acid $\left(\mathrm{C}_{22}\right)$. Such a specific and strong response of the carbon skeleton length suggests that the inhibition of biofilm formation was not simply due to the surfactant effect of monoacylglycerols and this suggestion was supported by no significant difference on the cell surface hydrophobicity change of $S$. mutans by monocaprin, monolaurin, and monocaprin (Additional file 1: Fig. 3).

Two specific carbon skeleton length regions for the inhibition of biofilm formation suggested two distinct response mechanisms to monoacylglycerols in bacteria. However, the existence of both response mechanisms in bacteria is strain specific. A. hydrophila, whose biofilm formation was not changed by monoacylglycerols, might not have any response mechanism. S. mutans and X. ory$z a e$, whose biofilm formation was inhibited by molecules around both monolaurin and monobehenin, might possess both response mechanisms. $Y$. enterocolitica, whose biofilm formation was inhibited by molecules around only monobehenin, might have one corresponding response mechanism. The biological mechanism of each response mechanism for the inhibition of biofilm formation by monoacylglycerols is unknown. However, the preventive effect of monolaurin on caries in rats by reducing the CFU number of $S$. mutans in a previous study (Lynch et al. 1983) supports our observation.

To test the inhibitory activity of monolaurin on biofilm formation in S. mutans, one of the continuous culture systems had been adapted and the biofilm structures were observed under a microscope (Figs. 3, 4). Because monolaurin was dissolved in methanol, the methanol 


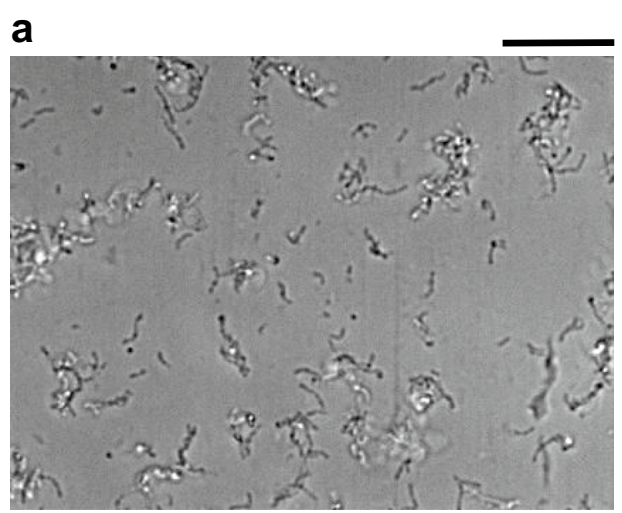

Control

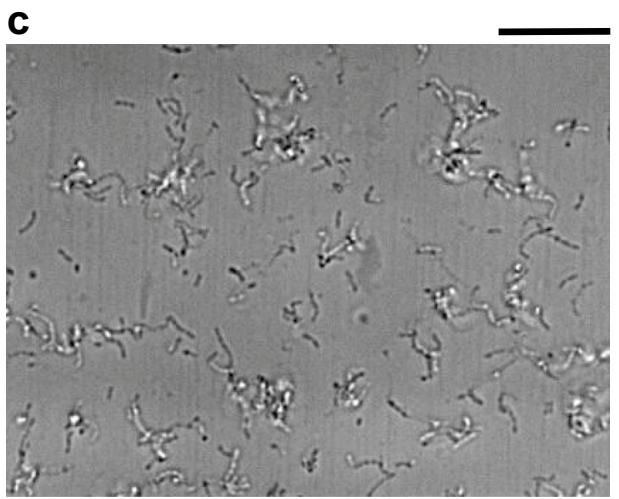

$95 \mathrm{mg} / \mathrm{l} \mathrm{monolaurin}$ and $0.48 \% \mathrm{MeOH}$

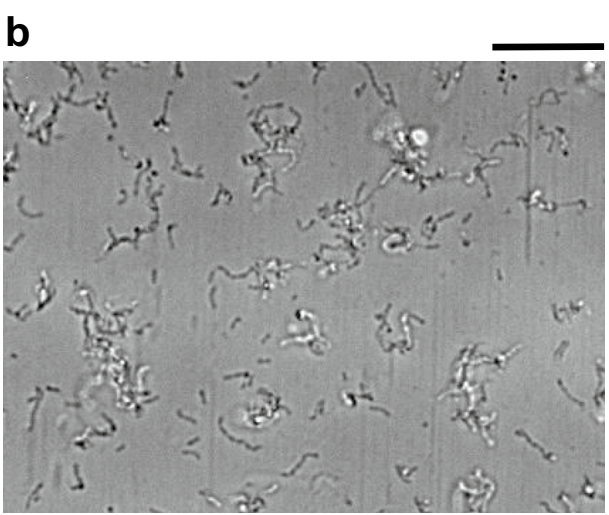

$0.48 \% \mathrm{MeOH}$

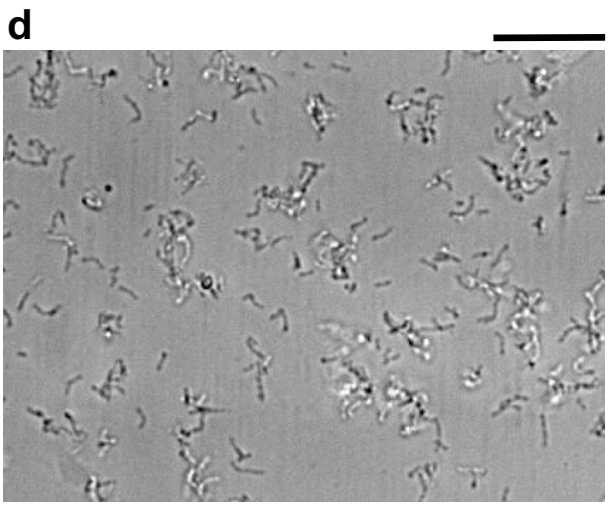

$190 \mathrm{mg} / \mathrm{l}$ monolaurin and $0.48 \% \mathrm{MeOH}$

Fig. 3 Biofilm formation of S. mutans in a continuous flow cell culture after a 1-h incubation in order to observe the initial attachment of cells. Cells were incubated in a BHI-S media, b BHI-S media with $0.48 \%$ methanol, c BHI-S media with $0.48 \%$ methanol and 95 mg/l monolaurin, and d BHI-S media with $0.48 \%$ methanol and $190 \mathrm{mg} / \mathrm{l}$ monolaurin. The scale bar on the top right of pictures represents $20 \mathrm{\mu m}$

effect was first observed as a control. There was no significant change in biofilm formation in $0.48 \%$ methanol after either 1- or 24-h incubations (Figs. 3b, 4b, respectively). After a 1-h incubation, the initial attachment of S. mutans was indistinguishable from those of all four tested cultures (Fig. 3). However, biofilm formation after the 24-h incubation was inhibited significantly by 95 and $190 \mathrm{mg} / \mathrm{l} \mathrm{monolaurin} \mathrm{(Fig.} \mathrm{4c,} \mathrm{d).} \mathrm{Increasing} \mathrm{the}$ monolaurin concentration inhibited biofilm formation in $S$. mutans more. Monolaurin is a surfactant and can be easily expected to inhibit biofilm formation in bacteria by changing cell's hydrophobicity; however, monolaurin unexpectedly inhibited the development of biofilm instead of initial cell attachment. This observation solidified the suggestion that the inhibitory activity of monoacylglycerols was not due to their detergent characteristics 
a

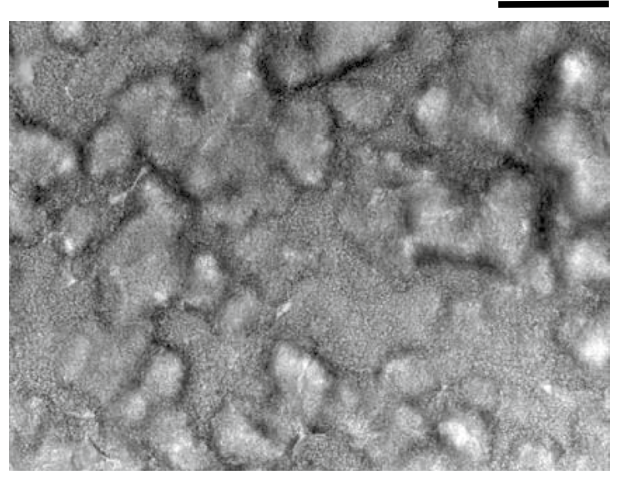

Control

C

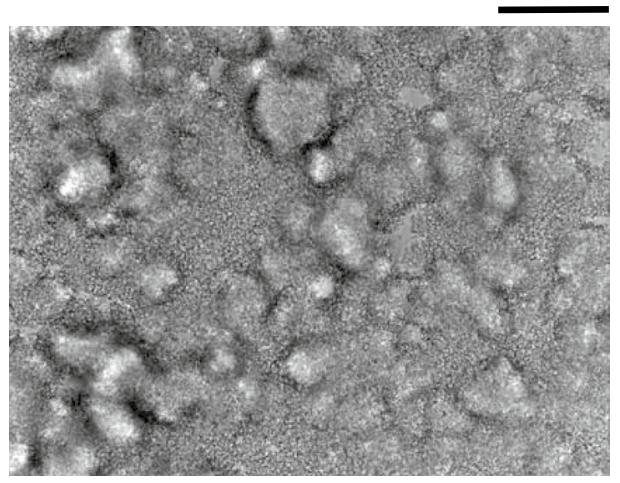

$95 \mathrm{mg} / \mathrm{l}$ monolaurin and $0.48 \% \mathrm{MeOH}$ b

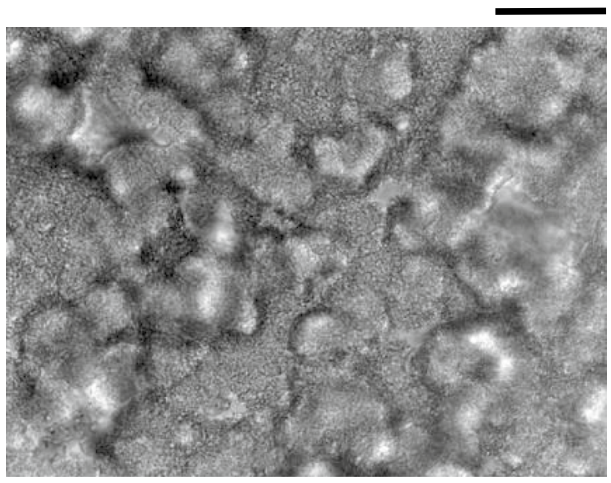

$0.48 \% \mathrm{MeOH}$

d

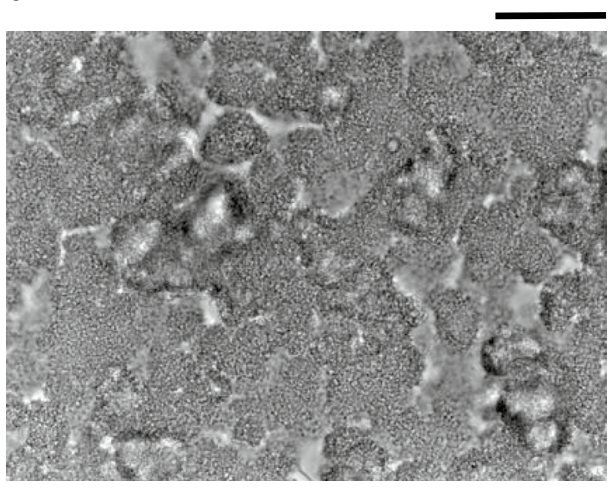

$190 \mathrm{mg} / \mathrm{l}$ monolaurin and $0.48 \% \mathrm{MeOH}$

Fig. 4 Biofilm formation of S. mutans in a continuous flow cell culture after a 24-h incubation in order to observe the biofilm development. Cells were incubated in a BHI-S media, b BHI-S media with $0.48 \%$ methanol, c BHI-S media with $0.48 \%$ methanol and 95 mg/l monolaurin, and $\mathbf{d}$ BHI-S media with $0.48 \%$ methanol and $190 \mathrm{mg} / \mathrm{l}$ monolaurin. The scale bar on the top right of the images represents $40 \mu \mathrm{m}$

but to changing cellular physiology by unknown response mechanisms for monoacylglycerols and therefore, biofilm formation as well. Additionally, the strong inhibition of monolaurin on biofilm formation in S. mutans suggests that monolaurin is the best oral hygiene compound among all tested monoacylglycerols.

\section{Conclusions}

Monoacylglycerols inhibited the biofilm formation of three bacterial strains, S. mutans, X. oryzae, and Y. enterocolitica, in a strain specific manner with two specific lengths of fatty acid moiety, monolaurin and monobehenin. This result suggested that biofilm formation was not inhibited by the detergent characteristics of monoacylglycerols. This suggestion was supported by the inhibitory action of monolaurin on biofilm development but not on the initial cell attachment of $Y$. enterocolitica in flow cytometric observation.

\section{Additional file}

Additional file 1. Figure S1. Effect of monoacylglycerols on the biofilm formation of four bacterial strains, (A) A. hydrophila, (B) S. mutans, (C) Y. enterocolitica, and (D) X. oryzae. The biofilm amount was evaluated with $1 \%$ crystal violet. Data points are the average of eight experiments and are presented as mean $\pm \mathrm{SD}$. The tested monoacylglycerols were monocaprylin (open square), monocaprin (closed square), monolaurin (open diamond), monomyristin (closed diamond), monopalmitin (open triangle), monostearin (closed triangle), monoarachidin (open circle ), and monobehenin (closed circle). Figure S2. Effect of monoacylglycerols on the cell growth of S. mutans. The relative cell density was evaluated by spectroscopic absorbance change at $595 \mathrm{~nm}$. Data points are the average of eight experiments and are presented as mean \pm SD. The tested monoacylglycerols were monocaprylin (open square), monocaprin (closed square), monolaurin (open diamond), monomyristin (closed diamond), monopalmitin (open triangle), monostearin (closed triangle), monoarachidin (open circle), and monobehenin (closed circle). Please note that the missing data when compared with Fig. S1 was due to the turbidity cause by insolubility of monoacylglycerols. Figure S3. Effect of monocaprin, monolaurin, and monomyristin on the hydrophobicity of cell surface of S. mutans. The experiment was performed according to a previous study (Infect Immun, 2004, 72(10): 6032-6039). 


\section{Authors' contributions}

$\mathrm{YH}$ designed and carried out all experiments. TJK provided idea of this study, drawn the figures, and wrote this manuscript. Both authors read and approved the final manuscript.

\section{Acknowledgements}

This work was supported by a Grant from the Next-Generation BioGreen 21 program (No. PJ011806022016), Rural Development Administration, Republic of Korea.

\section{Competing interests}

The authors declare that they have no competing interests.

Received: 2 June 2016 Accepted: 31 August 2016

Published online: 09 September 2016

\section{References}

Abdel-Haq NM, Asmar Bl, Abuhammour WM, Brown WJ (2000) Yersinia enterocolitica infection in children. Pediatr Infect Dis J 19:954-958

Batovska D, Todorova I, Tsvetkova I, Najdenski H (2009) Antibacterial study of the medium chain fatty acids and their 1-monoglycerides: individual effects and synergistic relationships. Pol J Microbiol 58:43-47

Beckloff N, Laube D, Castro T, Furgang D, Park S, Perlin D, Clements D, Tang H, Scott RW, Tew GN, Diamond G (2007) Activity of an antimicrobial peptide mimetic against planktonic and biofilm cultures of oral pathogens. Antimicrob Agents Chemother 51:4125-4132

Buňková L, Buňka F, Janiš R, Krejčí J, Doležálková I, Pospíšil Z, Růžička J, Tremlová B (2011) Comparison of antibacterial effect of seven 1-monoglycerides on food-borne pathogens or spoilage bacteria. Acta Vet Brno 80:29-39

Chavant P, Gaillard-Martinie B, Hébraud M (2004) Antimicrobial effects of sanitizers against planktonic and sessile Listeria monocytogenes cells according to the growth phase. FEMS Microbiol Lett 236:241-248

Coenye T, Honraet K, Rigole P, Jimenez PN, Nelis HJ (2007) In vitro inhibition of Streptococcus mutans biofilm formation on hydroxyapatite by subinhibitory concentrations of anthraquinones. Antimicrob Agents Chemother 51:1541-1544

Forssten SD, Björklund M, Ouwehand AC (2010) Streptococcus mutans, caries and simulation models. Nutrients 2:290-298

Hess DJ, Henry-Stanley MJ, Wells CL (2014) Antibacterial synergy of glycerol monolaurate and aminoglycosides in Staphylococcus aureus biofilms. Antimicrob Agents Chemother 58:6970-6973

Khalil MAM, Rehman A, Kashif WU, Rangasami M, Tan J (2013) A rare case of Aeromonas hydrophila catheter related sepsis in a patient with chronic kidney disease receiving steroids and dialysis: a case report and review of Aeromonas infections in chronic kidney disease patients. Case Rep Nephrol 2013:1-5

Kim T-J, Young BM, Young GM (2008) Effect of flagellar mutations on Yersinia enterocolitica biofilm formation. Appl Environ Microbiol 74:5466-5474

Kirov SM, Castrisios M, Shaw JG (2004) Aeromonas flagella (polar and lateral) are enterocyte adhesins that contribute to biofilm formation on surfaces. Infect Immun 72:1939-1945

Koornhof HJ, Smego RA Jr, Nicol M (1999) Yersiniosis II: the pathogenesis of Yersinia infections. Eur J Clin Microbiol Infect Dis 18:87-112

Lester K, Simmonds RS (2012) Zoocin A and lauricidin in combination reduce Streptococcus mutans growth in a multispecies biofilm. Caries Res 46:185-193

Lynch P, Schemmel RA, Kabara JJ (1983) Anticariogenicity of dietary glycerol monolaurin in rats. Caries Res 17:131-138

Marounek M, Putthana V, Benada O, Lukešová D (2012) Antimicrobial activities of medium-chain fatty acids and monoacylglycerols on Cronobacter sakazakii DBM 3157T and Cronobacter malonaticus DBM 3148. Czech Food Sci 30:573-580
McGarey D, Milanesi L, Foley D, Reyes BJ, Frye L, Lim D (1991) The role of motile aeromonads in the fish disease, ulcerative disease syndrome (UDS). Experientia 47:441-444

Oh D-H, Marshall DL (1996) Monolaurin and acetic acid inactivation of Listeria monocytogenes attached to stainless steel. J Food Protect 59:249-252

Ósk Thorgeirsdóttir T, Kristmundsdóttir T, Thormar H, Axelsdóttir I, Peter Holbrook W (2006) Antimicrobial activity of monocaprin: a monoglyceride with potential use as a denture disinfectant. Acta Odontol Scand 64:21-26

Park H-S, Ham Y, Shin K, Kim Y-S, Kim T-J (2015) Sanitizing effect of ethanol against biofilms formed by three Gram-negative pathogenic bacteria. Curr Microbiol 71:70-75

Parsek MR, Singh PK (2003) Bacterial biofilms: an emerging link to disease pathogenesis. Annu Rev Microbiol 57:677-701

Rouse MS, Rotger M, Piper KE, Steckelberg JM, Scholz M, Andrews J, Patel $R$ (2005) In vitro and in vivo evaluations of the activities of lauric acid monoester formulations against Staphylococcus aureus. Antimicrob Agents Chemother 49:3187-3191

Ruzin A, Novick RP (1998) Glycerol monolaurate inhibits induction of vancomycin resistance in Enterococcus faecalis. J Bacteriol 180:182-185

Ruzin A, Novick RP (2000) Equivalence of lauric acid and glycerol monolaurate as inhibitors of signal transduction in Staphylococcus aureus. J Bacteriol 182:2668-2671

Schlievert PM, Peterson ML (2012) Glycerol monolaurate antibacterial activity in broth and biofilm cultures. PLoS ONE 7:e40350

Schlievert PM, Deringer JR, Kim MH, Projan SJ, Novick RP (1992) Effect of glycerol monolaurate on bacterial growth and toxin production. Antimicrob Agents Chemother 36:626-631

Shen Y, Ronald P (2002) Molecular determinants of disease and resistance in interactions of Xanthomonas oryzae pv. oryzae and rice. Microbes Infect 4:1361-1367

Smego RA, Frean J, Koornhof HJ (1999) Yersiniosis I: microbiological and clinicoepidemiological aspects of plague and non-plague Yersinia infections. Eur J Clin Microbiol Infect Dis 18:1-15

Struzycka I (2014) The oral microbiome in dental caries. Pol J Microbiol 63:127-135

Thanomsub B, Watcharachaipong T, Chotelersak K, Arunrattiyakorn P, Nitoda T, Kanzaki H (2004) Monoacylglycerols: glycolipid biosurfactants produced by a thermotolerant yeast, Candida ishiwadae. J Appl Microbiol 96:588-592

Tsuge S, Furutani A, Fukunaka R, Oku T, Tsuno K, Ochiai H, Inoue Y, Kaku H, Kubo Y (2002) Expression of Xanthomonas oryzae pv. oryzae hrp genes in XOM2, a novel synthetic medium. J Gen Plant Pathol 68:363-371

Vetter SM, Schlievert PM (2005) Glycerol monolaurate inhibits virulence factor production in Bacillus anthracis. Antimicrob Agents Chemother 49:1302-1305

Wen ZT, Baker HV, Burne RA (2006) Influence of BrpA on critical virulence attributes of Streptococcus mutans. J Bacteriol 188:2983-2992

Zhang Y, Wei C, Jiang W, Wang L, Li C, Wang Y, Dow JM, Sun W (2013) The HDGYP domain protein RpfG of Xanthomonas oryzae pv. oryzicola regulates synthesis of extracellular polysaccharides that contribute to biofilm formation and virulence on rice. PLOS ONE 8:e59428

\section{Submit your manuscript to a SpringerOpen ${ }^{\odot}$ journal and benefit from:}

- Convenient online submission

- Rigorous peer review

- Immediate publication on acceptance

- Open access: articles freely available online

High visibility within the field

- Retaining the copyright to your article

Submit your next manuscript at springeropen.com 